\title{
Comparative Study of Malondialdehyde Levels and Lipid Profile in Patients with Myocardial Infarction and In Individuals without Myocardial Infarction, But With Coronary Risk Factors.
}

\author{
Dr.Ch.Venkata Ramana M.D. ${ }^{1}$, Dr.V.Sriramulu M.D. ${ }^{2}$ \\ ${ }^{1}$ Assoc. Professor, Dept. of Biochemistry, Guntur Medical College, Guntur, India \\ ${ }^{2}$ Professor, Dept. of Biochemistry, Guntur Medical College, Guntur, India
}

\begin{abstract}
:
INTRODUCTION:Coronary Artery Disease (C.A.D.) occurs due to blockage of Coronary arteries by atheroma, leading to inadequate blood supply to heart muscle compared to its need. Manifestations of C.A.D. vary from angina, Myocardial Infarction (M.I.) arrhythmia to sudden death. Oxidative modification of lipoproteins due to lipid peroxidation by free radicals will enhance atheroma formation, aggravating C.A.D. and leading to M.I., the severity of which can be assessed by MALONDIALDEHYDE (MDA) estimation.AIM OF STUDY:The aim of present study is whether MDA level can be used as marker of M.I. and to see whether the different risk factors like smoking, Hypertension (HTN), Diabetes Mellitus (DM), Obesity and Alcohol causing peroxidative damage and dyslipoproteinemia will show additive effect in relation to MDA levels.MATERIALS AND METHODS:The study population consisted of 3 groups of subjects. Group I Cases with coronary risk factors and with M.I.Group II - Cases with coronary risk factors, but without M.I. Group III - Healthy Normals. In these 3groups Lipid profile and Serum MDA level was estimated by Thiobarbituric acid method.RESULTS:Lipid peroxidative damage is found to be associated with all the Risk Factors studied namely HTN, D.M., Obesity, Alcohol and Smoking either singly or in different combinations as evidenced by elevation of MDA, Triglycerides, total cholesterol and LDL cholesreol and a fall of HDL.CONCLUSION:C.A.D. is a multi factorial process, with no individual factor strictly essential or sufficient for causation of M.I. In-variably the hazard posed by any particular risk factor is markedly influenced by other risk factors that are often associated.
\end{abstract}

Key Words: Coronary Artery Disease (C.A.D), Myocardial Infarction (M.I), Malondialdehyde (MDA), Hypertension (HTN), Diabetes Mellitus (D.M).

\section{Introduction:}

Coronary Artery Disease (C.A.D.) occurs due to blockage of Coronary arteries by atheroma, leading to inadequate blood supply to heart muscle compared to its need. Manifestations of C.A.D. vary from angina, Myocardial Infarction (M.I.) arrhythmia to sudden death. Oxidative modification of lipoproteins occurs due to lipid per oxidation of polyunsaturated fatty acids ${ }^{(1)}$. The polyunsaturated fatty acids can be oxidized either by cyclooxygenase system of enzymes or by oxygen free radicals. Though very low density lipoproteins (VLDL), high density lipoproteins (HDL) and LDL are all substrates for lipid per oxidation it is the LDL which bears the major brunt ${ }^{(2)}$.Oxidatively modified LDL is not a molecule identical with LDL. It consists of many modified lipids and proteins. Modifications of lipids include formation of hydroperoxides, lysophospholipids, oxysterols and aldehydic break down products of fatty acids, while modifications of apoprotein moiety includes breaks in peptide backbone as well as derivatization of certain aminoacid residues (typically the side chain amino group of lysine) with components of oxidized lipids including Malondialdehyde (MDA). There is a lot of evidence correlating the level of MDA and the severity of atherosclerosis. M.I. has been found to be associated with greater elevation of MDA levels - a reflection of platelet aggregation and peroxidative damage ${ }^{(3)}$.

\section{Aim Of Study:}

The aim of present study is whether MDA level can be used as marker of M.I. and to see whether the different risk factors like smoking, Hypertension (HTN), Diabetes Mellitus (DM), Obesity and Alcohol causing peroxidative damage and dyslipoproteinemia will show additive effect in relation to MDA levels.

\section{Materials And Methods :}

The study population consisted of 3 groups of subjects. Group I -50 Cases with coronary risk factors and with M.I.,admitted in Govt. General Hospital Gunturfrom 1-6-13 to 31-12-13.Group II - 50 Cases with coronary risk factors, but without M.I. Group III -50 Healthy Normals. In these 3 groups Serum MDA level 
was estimated by Thiobarbituric acid method ${ }^{(4)}$. Total serum cholesterol was estimated by ZLATKS, ZAK and BOYLE method. High density lipoprotein cholesterol was assessed by phosphotungstate - Magnesium chloride precipitation method. (ref. BURSTEIN, M. SCHOLNICK, H.R. AND MORFIN 1970). Serum triglycerides were estimated by Acetyl acetone method.VLDL Cholesterol was calculated by using Friedewalds formula.

VLDL Cholesterol $=\frac{\text { Triglycerides }}{5} m g \%$

\section{LDLCholesterol $=$ Total Cholesterol $-($ HDLCholesterol + VLDLCholesterol $) m g \%$}

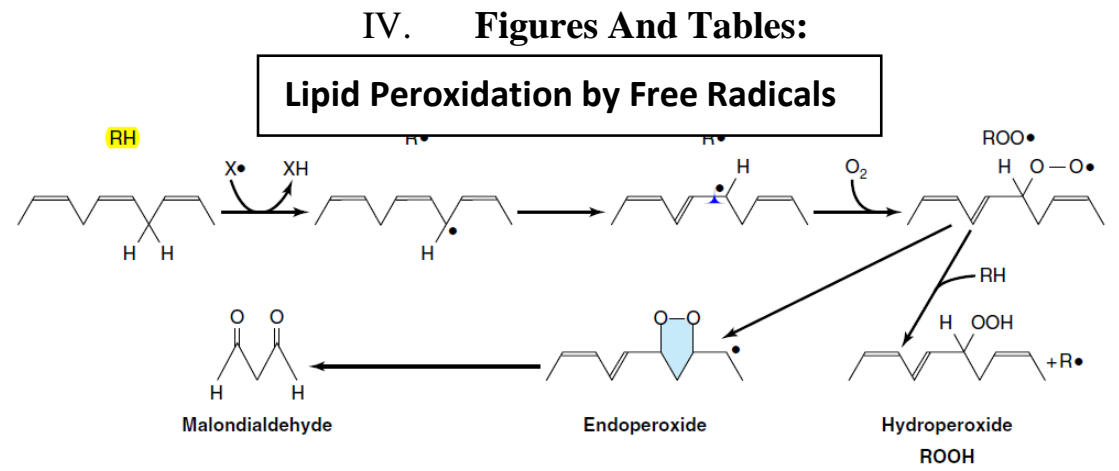

Table - 1

MDA AND LIPID PROFILE (MEAN + S.D.) IN CONTROLS,

RISK GROUP WITHOUT M.I. AND CASES WITH M.I.

\begin{tabular}{|l|l|l|l|l|}
\hline S.No. & Name of the parameter & Controls & $\begin{array}{l}\text { Risk Group without } \\
\text { M.I. }\end{array}$ & Cases with M.I. \\
\hline 1. & MDA (nmol./100ml) & $260 \pm 39$ & $449 \pm 77$ & $577 \pm 87$ \\
\hline 2. & Triglycerides $(\mathrm{mg} / 100 \mathrm{ml})$ & $125 \pm 22$ & $262 \pm 61$ & $268 \pm 56$ \\
\hline 3. & Total Cholesterol $(\mathrm{mg} / 100 \mathrm{ml})$ & $173 \pm 22$ & $236 \pm 61$ & $259 \pm 54$ \\
\hline 4. & VLDL Cholesterol $(\mathrm{mg} / 100 \mathrm{ml})$ & $25 \pm 5$ & $51 \pm 12$ & $53 \pm 11$ \\
\hline 5. & HDL Cholesterol $(\mathrm{mg} / 100 \mathrm{ml})$ & $44 \pm 4$ & $38 \pm 3$ & $31 \pm 4$ \\
\hline 6. & LDL Cholesterol $(\mathrm{mg} / 100 \mathrm{ml})$ & $104 \pm 12$ & $144 \pm 20$ & $188 \pm 21$ \\
\hline
\end{tabular}

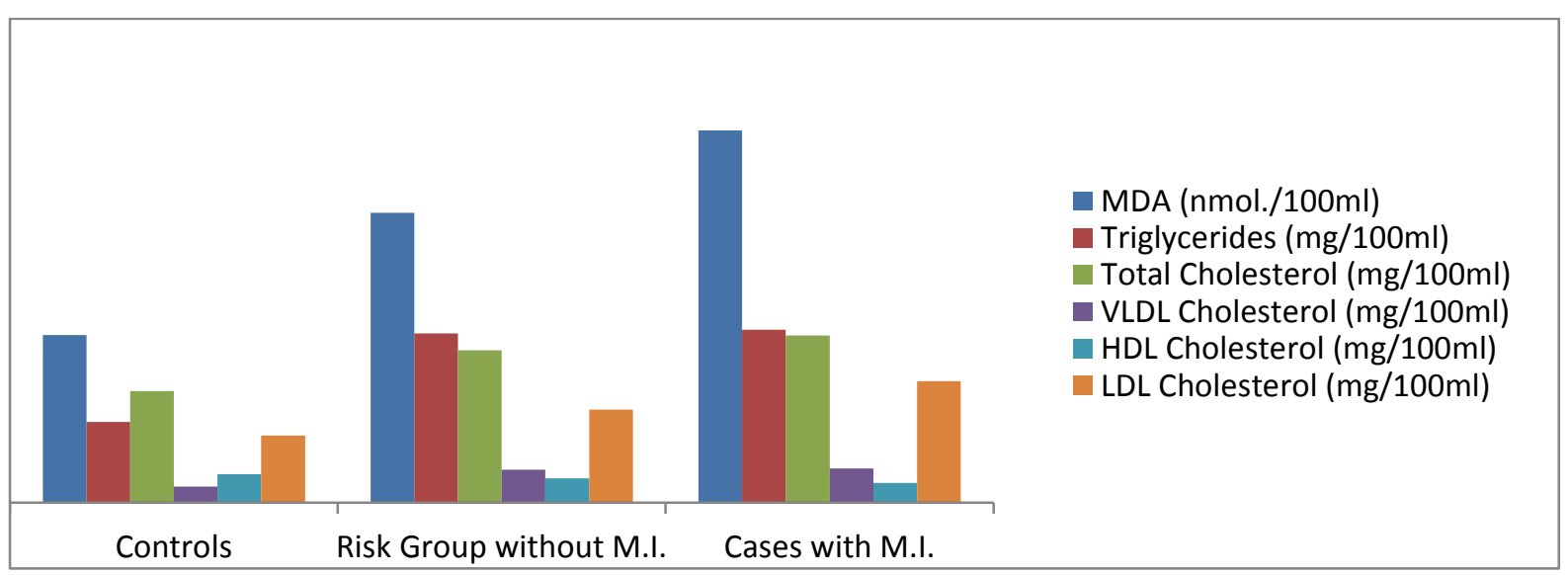

Table - 2

Serum MDA levels (mean value n mol./100ml)

\begin{tabular}{|l|l|l|}
\hline Associated risk factors & Cases with M.I. & $\begin{array}{l}\text { Risk Group } \\
\text { without M.I. }\end{array}$ \\
\hline HTN & 507 & 419 \\
\hline D.M. & 500 & 425 \\
\hline D.M. + Obesity & 527 & 459 \\
\hline HTN + D.M + Obesity & 553 & 478 \\
\hline HTN + Smoking & 650 & 582 \\
\hline HTN + Alcohol & 527 & 437 \\
\hline
\end{tabular}


Table - 3

Serum Triglyceride levels (mean value $\mathrm{mg} / \mathbf{1 0 0 m \mathrm { m } )}$

\begin{tabular}{|l|l|l|}
\hline Associated risk factors & Cases with M.I. & $\begin{array}{l}\text { Risk Group } \\
\text { without M.I. }\end{array}$ \\
\hline HTN & 226 & 197 \\
\hline D.M. & 341 & 291 \\
\hline D.M. + Obesity & 325 & 350 \\
\hline HTN + D.M + Obesity & 325 & 325 \\
\hline HTN + Smoking & 262 & 262 \\
\hline HTN + Alcohol & 255 & 220 \\
\hline
\end{tabular}

Table - 4

Total Cholesterol (mean value $\mathbf{m g} / \mathbf{1 0 0 m l}$ )

\begin{tabular}{|l|l|l|}
\hline Associated risk factors & Cases with M.I. & $\begin{array}{l}\text { Risk Group } \\
\text { without M.I. }\end{array}$ \\
\hline HTN & 267 & 238 \\
\hline D.M. & 288 & 261 \\
\hline D.M. + Obesity & 290 & 260 \\
\hline HTN + D.M + Obesity & 313 & 268 \\
\hline HTN + Smoking & 256 & 212 \\
\hline HTN + Alcohol & 265 & 223 \\
\hline
\end{tabular}

Table - 5

LDL Cholesterol (mean value $\mathbf{m g} / \mathbf{1 0 0 m l}$ )

\begin{tabular}{|l|l|l|}
\hline Associated risk factors & Cases with M.I. & $\begin{array}{l}\text { Risk Group } \\
\text { without M.I. }\end{array}$ \\
\hline HTN & 192 & 158 \\
\hline D.M. & 192 & 168 \\
\hline D.M. + Obesity & 191 & 149 \\
\hline HTN + D.M + Obesity & 216 & 147 \\
\hline HTN + Smoking & 179 & 125 \\
\hline HTN + Alcohol & 177 & 134 \\
\hline
\end{tabular}

Table - 6

HDL Cholesterol (mean value mg./100ml)

\begin{tabular}{|l|l|l|}
\hline Associated risk factors & Cases with M.I. & $\begin{array}{l}\text { Risk Group } \\
\text { without M.I. }\end{array}$ \\
\hline HTN & 29 & 38 \\
\hline D.M. & 31 & 39 \\
\hline D.M. + Obesity & 34 & 37 \\
\hline HTN + D.M + Obesity & 32 & 33 \\
\hline HTN + Smoking & 28 & 36 \\
\hline HTN + Alcohol & 37 & 45 \\
\hline
\end{tabular}

\section{Discussion:}

Serum MDA levels are greatly increased in cases with M.I., (mean of $577 \pm 87 \mathrm{nmol} . / 100 \mathrm{ml}$.) while moderately increased in patients with risk factors without M.I. (mean of $449 \pm 77 \mathrm{nmol} . / 100 \mathrm{ml}$.) as compared to normals (mean of $260 \pm 39 \mathrm{nmol} . / 100 \mathrm{ml}$.). In smokers, with setting in of M.I. there is great elevation of MDA, the value of $650 \mathrm{nmol} . / 100 \mathrm{ml}$. The action of nicotine on the endothelial cell resulting in release of Endothelin I and Endothelin-II and the endothelium derived contracting factors including thromboxane or thicyanate may be responsible for such a severe peroxidative damage. So, if MDA is to be used as a marker of M.I. a separate yardstick is to be considered when smokers are involved.

Serum triglyceride levels also showed elevation with all the risk factors. With setting in of M.I., the values showed further elevation. Marked elevation of triglycerides i.e., around $300 \mathrm{mg} \%$ is seen in D.M., D.M. + obesity and D.M. + HTN + obesity. The reasons for such an elevation of triglycerides in D.M. are 1) increased flow of free fatty acids and glucose to liver due to impaired glucose utilization and 2) defect in clearance of VLDL triglycerides due to decreased lipoprotein lipase activity. Obese persons have resistance to the action of insulin because of decreased number of functioning receptors for insulin on the cell surface. The insulin resistance may cause overproduction of VLDL Triglycerides. The elevation of triglycerides in smokers can be explained on the assumption that smoking causes increased release of free fatty acids from adipose tissue. These free fatty acids are partly extracted by liver and incorporated into Triglycerides.

Total cholesterol also is found to be elevated with all the risk factors and the values further increased with setting in of infarction. In Diabetics due to insulin deficiency and in Obese due to insulin resistance fatty acids 
are catabolised to produce acetyl CoA, which can not be readily utilized in the TCA cycle as the availability of oxaloacetate is reduced, thus rendering TCA cycle sluggish. So, acetyl CoA pool is increased and is channeled into cholesterol synthesis. In Smokers, nicotine of cigarette will cause lipolysis and thereby increase the acetyl $\mathrm{CoA}$ and cholesterol synthesis.

LDL cholesterol is elevated in risk group and it showed a further increase with M.I. The peroxidation of LDL with the risk factors prolongs the half life of LDL and thus is responsible for the elevation of LDL in risk factors. With setting in of M.I. the greater peroxidative damage leads to further elevation. However in D.M. there are a number of factors to account for the elevation of LDL namely 1) Decreased clearance rate for LDL Apo B 2) defective LDL clearance due to insulin resistance or relative insulin deficiency 3) alteration in the composition namely increase in the proportion of triglyceride in LDLand greater density which leads to decreased ability to bind to receptors 4) an abnormal lipoprotein in the LDL range that contains Apo E, which appears to stimulate cholesteryl ester accumulation 5) non enzymatic glycation of Apo B decreases LDL catabolism 6) glycated LDL also appears to exhibit altered interactions with endothelial cells and to enhance cholesteryl ester synthesis in macrophages and 7) because of a block in the cholesteryl ester transfer activity particularly in N.I.D.D.M. there is an increase in free cholesterol content of LDL which may result in increased atherogenecity.

HDL cholesterol was found to be decreased in risk factors and with setting in of M.I. there was a greater fall. In Diabetes Mellitus the low lipoprotein lipase actibity causing an impairment of lipolysis of VLDL leads to a reduction in the formation of HDI. The fall in HDL level in smokers has been reported to be independent of age, obesity, alcohol, hormone use and exercise. It is also pointed out by many workers that the HDL level in smokers is inversely proportional to the level of serum thiocyanate ${ }^{(5)}$. However it was noticed that there was no fall in HDL in HTN associated woth alcohol. As per the existing data alcoholics show an elevation of HDL cholesterol ${ }^{(6)}$ due to induction of hepatic microsomal enzymes that are associated with synthesis of HDL. Probably because of this fact, alcoholics with HTN did not show fall in HDL level in our study.

\section{Conclusion:}

C.A.D. is a multifactorial process, with no individual factor strictly essential or sufficient for causation of M.I. In-variably the hazard posed by any particular risk factor is markedly influenced by other risk factors that are often associated.Though the MDA levels increased with addition of risk factors for example, D.M. + Obesity + HTN > D.M. + Obesity > D.M. the increase is not found to be additive arithmetically.

\section{References:}

[1]. HALLIWELL B, GUTTERIDGE JMC- lipid peroxidation; a radical chain reaction in ; HALLIWELL B, GUTTERIDGE JMC, EDITORS. Free Radicals in Biology and Medicine. OXFORD CLARENDON PRESS, 1985; 138-45.

[2]. NISHIGAKI I, HAGIHARA M TSUNEKAWAH; MASEKI M. YAGI K - Lipid peroxide levels of serum lipoprotein fractions of Diabetic patients. BIOCHEM MED 1981: 25; 373-8.

[3]. REAVEN G.M. LITHALL H and LAUDSBURG 1996 N.ENG. J. MED. 334: 374-381.

[4]. Mahfouz. M.O., hariprasad, C.H. Shaaffie. I.A. and Sadasivudu B 1986 IRCS Med Sci 14 1110, 1111

[5]. Criqui.M.H. Wallace R.B. Heiss. G., et al; Cigarette smoking and plasma high-density lipoprotein cholesterol. The lipid research clinics program prevalence study. Circulation, 62 (supp. IV): IV - 70 to IV - 76, 1980.

[6]. Ronald M. Krauss: Regulation of High Density Lipoprotein Levels; The medical Clinics of North America - 66: 403-425. 